\title{
Vírus da Estomatite Vesicular (Sorotipo Indiana 2) Como Modelo Experimental Para o Estudo de Encefalite Aguda - Aspectos Morfológicos
}

\section{Vesicular Stomatitis Virus (Indiana 2 Serotype) as Experimental Model to Study Acute Encephalitis - Morphological Features}

\author{
G. F. Machado ${ }^{1}$, L. Chimelli, F. Figueiredo ${ }^{2 *}$
}

Resumo

\begin{abstract}
O vírus da estomatite vesicular (VEV) é um Vesiculovírus da família Rhabdoviridae que infecta mamíferos e causa lesões vesiculares semelhantes às observadas na febre aftosa. A encefalite experimental pode ser induzida em roedores e os sintomas são semelhantes aos observados na raiva; entretanto, as lesões observadas no encéfalo dos animais são diferentes. Corpúsculos de inclusão não são observados, há necrose especialmente da região do bulbo olfatório e em alguns casos, ventriculite. Observamos que o padrão temporal de disseminação do VEV e os aspectos morfológicos das lesões são similares aos descritos na literatura. $\mathrm{O}$ vírus parece se disseminar através dos ventrículos cerebrais, multiplicando-se em células do epêndima e em neurônios, além de utilizar o transporte retrógado e anterógrado. Constatamos que devido à facilidade de manipulação do vírus, este modelo experimental tem sido utilizado em inúmeros trabalhos de pesquisa em diversas áreas. Se por um lado, os relatos sobre a patogenia da infecção são numerosos, por outro lado, ainda existem muitas lacunas que envolvem, por exemplo, aspectos sobre a transmissão do vírus, a recuperação dos animais infectados e a participação de células gliais durante a fase aguda e a fase de recuperação dos animais.
\end{abstract}

Palavras chave: Vírus da Estomatite Vesicular, Encefalite Aguda, Modelo Experimental, Camundongo.

\begin{abstract}
The Vesicular Stomatitis Virus (VSV) is a Vesiculovirus of the Rhabdoviridae family that infects mammals and causes vesicular lesions similar to those of foot-and-mouth disease. VSV experimental encephalitis can be induced in rodents and the symptoms are similar to those observed in rabies. However, the lesions observed in the animals' encephalon are different. Inclusion bodies are not observed. There is necrosis, particularly in the region of the olfactory bulb, and, in some cases, ventriculitis. It was observed that the time pattern of VSV dissemination and the morphological aspects of the lesions are similar to those described in literature. The virus seems to be disseminated through the brain ventricles, being multiplied in the ependyma cells and in the neurons, besides using retrograde and anterograde transport. It was noticed that, due to the facility of virus manipulation, this experimental model has been used in innumerable research studies in several fields. If, on the one hand there are plenty of reports on the infection pathogenesis, on the other hand there are many gaps involving, for instance, aspects about virus transmission, recovery of infected animals and participation of glial cells in the acute as well as in the recovery phases.
\end{abstract}

Key words: Vesicular Stomatitis Virus, Acute Encephalitis, Experimental Model, Mouse.

\footnotetext{
${ }^{1}$ Departamento de Patologia da Faculdade de Medicina da Universidade Federal do Rio de Janeiro-RJ

${ }^{2}$ Departamento de Patologia da Universidade Federal de Brasília-DF.
} 


\section{Introdução}

$\mathrm{O}$ vírus da estomatite vesicular (VEV) é um vírus RNA, de fita simples, do gênero Vesiculovírus (família Rhabdoviridae), capaz de infectar muitas espécies de mamíferos e, ocasionalmente, o homem (LETCHWORTH, 1999). Uma glicoproteína do envelope, denominada proteína-G, é responsável pela indução de anticorpos neutralizantes e distingue os principais sorotipos do vírus: Indiana e New Jersey (KELLEY et al., 1972).

Existe similaridade entre as lesões vesiculares causadas pelo VEV e pelo vírus da febre aftosa, e os prejuízos econômicos aliados à infecção clínica são consideráveis, motivo pelo qual os surtos desta doença sejam mantidos sob controle estrito pelas agências de Vigilância Sanitária de alguns países, incluindo o Brasil. A estrutura relativamente simples desse vírus, a alta capacidade de replicação e o rápido curso da doença fazem deste um bom modelo para estudos em morfologia, virologia, imunologia e em biologia molecular (LETCHWORTH, 1999).

A encefalite pelo VEV pode ser produzida por inoculação intracerebral ou intranasal (COX \& OLINTSKY, 1933 apud MYOSHI,. HARTER; HSU ) ou intranasal (SABIN E OLINTSKY, 1937a,1937b). Em uma série de trabalhos, SABIN E OLINTSKY (1937a，1937b, 1938a，1938b) demonstraram que camundongos jovens e velhos eram igualmente susceptíveis a encefalite após inoculação intracerebral. Os sintomas clínicos da infecção experimental pelo VEV são semelhantes aos produzidos pelo vírus da raiva, com paralisia seguida de morte do animal (WEYLAND et al., 1992).

O título do VEV no sistema nervoso central (SNC) geralmente atinge o pico em torno de 7-10 dias após a infecção e tem correlação com a mortalidade dos animais. Os camundongos que sobrevivem eliminam o vírus completamente do SNC sem lesão aparente (FORGER et al., 1991; HUNEYCUTT et al., 1994). Barrera \& Letchworth (1996) relataram a persistência de RNA viral em cérebro e cerebelo de hamsters 10-12 meses após a inoculação, mas não foi possível recuperar partículas infectantes do VEV. Animais que sobrevivem à infecção apresentam redução permanente de serotonina e também alteração permanente do comportamento (MOHAMMED et al., 1991).

Em camundongos, o VEV induz resposta mediada por linfócitos T citotóxicos (ROSENTHAL; ZINKERNAGEL, 1980) e por anticorpos neutralizantes (KELLEY et al., 1972). Segundo Gobet et al. (1988) e Leist et al. (1987), é a fração G das imunoglobulinas e não a ação de linfócitos $\mathrm{T}$ citotóxicos a responsável pela recuperação da infecção primária pelo vírus. Em estudos realizados "in vitro", Sy et al. (1983) observaram que a infecção pelo VEV resultava em eliminação funcional de uma sub população de células T supressoras, o que "in vivo" tornaria o animal incapaz de modular sua resposta imune.

Huneycutt et al. (1993) descreveram a migração do VEV inoculado via intranasal em camundongos BALB-c depletados de linfócitos $\mathrm{T} \mathrm{CD}^{+}{ }^{+}$ou $\mathrm{CD}^{+}$. Os resultados sugerem que embora as células $\mathrm{CD} 4^{+}$ ou $\mathrm{CD} 8^{+}$limitem a replicação viral e a disseminação transináptica ou ventricular, elas contribuem pouco para o desenvolvimento das alterações histopatológicas observadas.

Bi et al. (1995) relatam a produção de óxido nítrico, a expressão de moléculas do MHC, as características fenotípicas e a cinética de migração das células do infiltrado inflamatório após a infecção pelo VEV em camundongos Balb-c, demonstrando a importância da imunidade inata e adquirida neste modelo experimental. Entretanto, segundo estes autores, os mecanismos de defesa do hospedeiro e os mecanismos de eliminação do VEV durante a infecção do SNC permanecem obscuros. Avaliações semelhantes àquelas realizadas por Bi et al. (1995) foram feitas por Christian et al. (1996) em camundongos C57B16.

Komatsu et al.(1997). demonstraram que o tratamento de camundongos infectados com VEV 
com interleucina (IL)-12 resultava em redução da porcentagem de mortalidade e em menor recuperação de partículas infectantes. E, em uma publicação subseqüente, Komatsu, Barna e Reiss (1997) sugeriram que a IL-12 agiria diretamente sobre os neurônios, ativando-os e promovendo a eliminação das partículas virais através da produção de óxido nítrico.

Este trabalho teve como objetivo verificar as alterações morfológicas e a presença de antígeno viral no encéfalo de camundongos após a inoculação do vírus da estomatite vesicular por via intranasal, comparando os resultados com aqueles existentes na literatura e estabelecendo parâmetros para a utilização do modelo.

\section{Material e Métodos}

Para inoculação do VEV, foram utilizados 64 camundongos C57Bl6, mantidos pelo Biotério Central da Faculdade de Medicina de Ribeirão Preto (FMRP)-USP-SP, machos, com 25-30 dias de idade. Os animais foram divididos em lotes de 10 animais por caixa, e mantidos com água e ração "ad libitum".

A amostra do vírus da estomatite vesicular (VEV), foi gentilmente cedida pelo Prof. Dr. Aramis Augusto Pinto (UNESP - Departamento de Microbiologia - Faculdade de Ciências Agrárias e Veterinárias - Jaboticabal-SP). Procedeu-se à análise, por meio de reação de fixação do complemento segundo protocolo descrito por Camargo et al. (1950), de uma amostra para tipificação do vírus, que demonstrou a presença do sorotipo Indiana 2.

A amostra do vírus foi mantida em cultura de células BHK-21 de hamster (Brain/Hart/Kidney) congelada a $-80{ }^{\circ} \mathrm{C}$. Antes de fazer a inoculação nos animais, realizou-se a inoculação do vírus em camundongos para adaptação do mesmo à espécie. Dois grupos de 12-14 camundongos Swiss, machos com 5-7 semanas receberam inoculação intracerebral de $0,1 \mathrm{ml}$ da suspensão de células BHK. Esses animais começaram a apresentar sintomas 3-4 dias após a inoculação, quando foram sacrificados com éter. Procedeu-se então à retirada do encéfalo, que foi triturado em gral, adicionando-se $1 \mathrm{ml}$ de solução salina tamponada $(\mathrm{pH}=7,4)$ para cada $1 \mathrm{~g}$ de encéfalo. Para auxiliar a trituração do material, adicionou-se uma pequena quantidade de areia estéril. A suspensão de encéfalo foi tratada com Pentabiótico® durante 20-30 minutos em geladeira, centrifugada a 2000 rotações por minuto (rpm) e o sobrenadante utilizado para a inoculação intracerebral de outros 12-14 camundongos. A suspensão de vírus obtida da $4^{\text {a }}$ passagem intracerebral foi capaz de infectar os camundongos através de inoculação intranasal.

A partir da $4^{\text {a }}$ passagem, obtiveram-se $7 \mathrm{ml} \mathrm{de}$ sobrenadante do SNC que foram utilizados para a inoculação dos animais que compuseram os grupos experimentais. A amostra foi separada em alíquotas mantidas em freezer $-80{ }^{\circ} \mathrm{C}$, descongeladas apenas no momento da sua utilização. O título do inóculo em $\mathrm{TCID}_{50}$, calculado segundo o método de Reed \& Müench (1938), foi igual a $10^{5}$ vírus/ml.

Devido à alta susceptibilidade dos animais mais jovens e a maior resistência ao vírus dos animais mais velhos, previamente relatadas por Sabin \& Olintsky (1938a), a inoculação do vírus foi realizada em animais com 25-30 dias de idade, idade esta que foi previamente determinada em experimento piloto.

O volume do inóculo foi determinado pó meio de inoculação prévia de grupos de 10 camundongos com diferentes volumes da suspensão do vírus. Verificouse a ocorrência de mortalidade de $60 \%$ dos animais inoculados com $31 / 4$ da suspensão, volume este que também permitia aspiração adequada da gotícula. Os camundongos foram inoculados no dia 0 e sacrificados nos dias 2, 4 e 6 após a inoculação do vírus (pi) (Tabela 1).

Cada animal foi perfundido por via intracardíaca com cerca de 30-40 ml de PBS tamponado ( $\mathrm{pH} \mathrm{7,4)}$ e, em seguida, com 20-30 ml de solução de paraformoldeído a $4 \%$. Depois de serem retirados da caixa craniana, os encéfalos foram mantidos 
durante no máximo 12 horas em solução de paraformaldeído a 4\%, transferidos para uma solução de álcool a 70\% e incluídos em parafina segundo o procedimento padrão. Os encéfalos foram incluídos inteiros, para a obtenção de cortes horizontais e separados em dois hemisférios, para obtenção de cortes sagitais. Para a coloração pela hematoxilinaeosina (H-E) e para as reações de imunoistoquímica foram obtidos cortes de 51/4m seqüenciais.

Foram realizadas avaliações dos cortes histológicos corados pela $\mathrm{H}-\mathrm{E}$ dos camundongos dos grupos I e II, três vezes em tempos diferentes, em cada ponto de sacrifício, para a determinação da porcentagem das alterações observadas. Como controle normal, foram utilizados cortes dos encéfalos de animais do grupo II.

A distribuição de antígenos virais e dos astrócitos reativos a proteína glial fibrilar ácida foram avaliados pelo método $\mathrm{ABC}$ (complexo avidina biotina peroxidase) de imunoistoquímica. Os cortes foram desparafinados e hidratados e procedeu-se ao bloqueio da peroxidase endógena $\left(1 \% \mathrm{H}_{2} \mathrm{O}_{2}\right.$ em tampão fosfato (PBS), pH 7,4, 20 min). Após enxágüe três vezes em PBS+soroalbumina bovina (BSA) a $1 \%$, os cortes foram tratados com tripsina $(1 \%, 30$ min. $37^{\circ} \mathrm{C}$ ), lavados três vezes em PBS+BSA a $1 \%$ e os sítios inespecíficos foram bloqueados com leite em pó desnatado (Molico® $3 \%$ em PBS pH 7,4). Os cortes foram incubados "overnight" a $4^{\circ} \mathrm{C}$ com anticorpo primário anti-VEV (1:1000 fração gama produzida em cobaias no Departamento de Microbiologia da FCAV-UNESP) e anti-glial fibrillar acidic protein (GFAP) (1:300, Dako). Após a lavagem em PBS+BSA $1 \%$ (três vezes) foram incubados, respectivamente, com o anticorpo secundário anticobaia biotinilado (1:200, Vector) e anti-coelho (1:100, Dako) por 45 minutos no escuro. Em seguida ao enxágüe três vezes em $\mathrm{PBS}+\mathrm{BSA}$ a $1 \%$, procedeuse à incubação com complexo $\mathrm{AB}$ (1:100, Vector) por 45 minutos. Os cortes foram novamente lavados e a reação revelada com 3-Amino-9-Ethylcarbazole (AEC) (SIGMA) para marcação do VEV, com diaminobenzidina (DAB) para a marcação dos astrócitos e finalmente contracoradas com hematoxilina de Mayer. As lâminas coradas com AEC foram montadas em meio aquoso e aquelas coradas com DAB desidratadas e montadas em bálsamo. Para controle das reações inespecíficas utilizaram-se cortes seqüenciais onde o anticorpo primário foi suprimido. Fotomicrografias realizadas com câmera Ricoh acoplada a microscópio Hund H500.

Tabela 1- Número total de animais que constituíram cada grupo experimental.

\begin{tabular}{cccc}
\hline & \multicolumn{3}{c}{ Dias após a inoculação do vírus } \\
\hline & $2^{\mathrm{o}}$ & $4^{\mathrm{0}}$ & $6^{\mathrm{O}}$ \\
Grupo I & 14 & 17 & 18 \\
\multirow{2}{*}{ Grupo II } & 05 & 05 & 05 \\
\hline
\end{tabular}

Grupo I - Inoculação do vírus no dia 0;

Grupo II - Controle do vírus - instilação de PBS estéril nas narinas no dia 0 .

\section{Resultados}

Sintomas e evolução clínica.

Os sintomas foram observados em $60 \%$ dos animais quatro dias após a inoculação. Os camundongos inicialmente ficavam amontoados e com os pêlos arrepiados. No quinto dia, alguns animais apresentavam conjuntivite purulenta. Posteriormente, apresentavam dificuldade de caminhar que progredia para paralisia, observada primeiramente nos membros posteriores e depois também nos anteriores. Com o agravamento da paralisia, ocorria morte por insuficiência respiratória. Os camundongos que apresentavam paralisia de posteriores eram sacrificados para se evitar o sofrimento desnecessário da progressão dos sintomas antes da morte.

\section{Análise Histológica}

Caracterização morfológica das lesões.

As principais alterações morfológicas, inflamatórias e/ou degenerativas, observadas nos 
cortes corados pela hematoxilina-eosina nos três pontos de sacrifício dos animais estão relacionadas nas Figuras 1 B, C e D. Dois dias após a inoculação do vírus, as lesões foram discretas e localizadas no bulbo olfatório. A alteração observada em maior número de animais foi a presença de infiltrado inflamatório (leptomeningite) no bulbo olfatório. Um número pequeno de camundongos apresentou leptomeningite mais grave associada à necrose focal que foi caracterizada por presença de pequenos focos de rarefação do tecido nervoso e presença de debris celulares comprometendo aproximadamente $1 / 4 \mathrm{da}$ área do bulbo olfatório.

No quarto dia, houve agravamento do processo inflamatório e muitos animais apresentaram lesão inflamatória intensa, localizada na região basal do encéfalo, passando pelo quiasma óptico e alcançando o tronco cerebral. Ventriculite foi observada em uma pequena porcentagem dos camundongos.

No sexto dia após a inoculação do VEV, todos os animais examinados apresentavam algum tipo de comprometimento tecidual no bulbo olfatório. A lesão mais grave observada nesta região caracterizou-se pelo aspecto tumefeito e amolecido do tecido, correspondendo microscopicamente à necrose do tecido. Um pouco mais da metade dos camundongos apresentou leptomeningite disseminada, que atingia particularmente a base do encéfalo. Nesse caso, ela era geralmente acompanhada de ventriculite e presença de células inflamatórias no parênquima, infiltrado linfocitário perivascular, microglia em bastão e focos de necrose tecidual comprometendo regiões importantes como tálamo, hipotálamo e tronco cerebral.
A

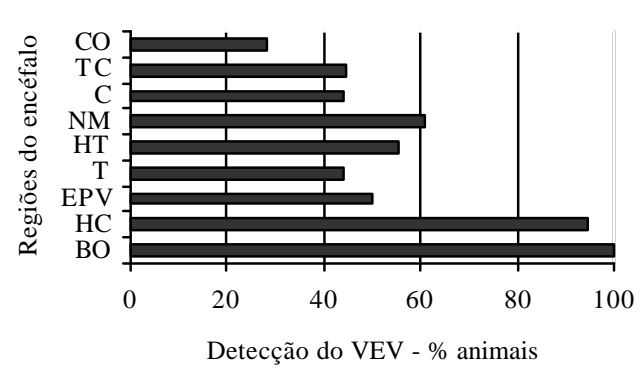

B

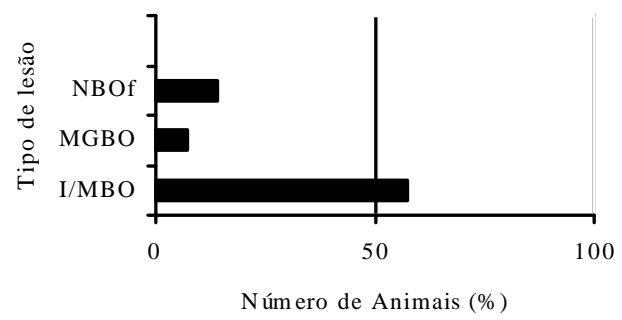

C

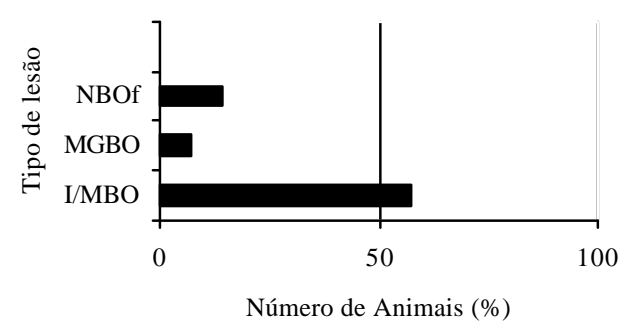

D

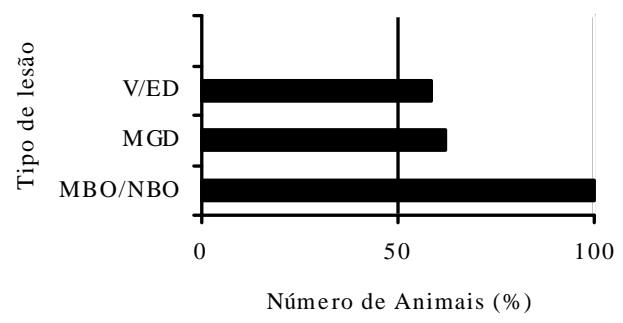

Figura 1 - A - Principais regiões do encéfalo onde os antigeros do vírus da estom atite vesicular foram localizados por imunoistoquímica. Principais alterações morfológicas observadas. B - no 20 dia pi, C - no 40 dia pi e D - no 60 dia pi I/ M BO - infiltrado inflamatório/Meningite discreta na região do bulbo olfatório, NBOf - Necrose focal na região do bulbo olfatório, MGBO - Meningite grave disseminada. V/MGD - Ventriculite associada à meningite grave disseminada MBO/ NBO - Meningite e/ou necrose na região do bulbo olfatório, MGD - Meningite grave disseminada, V/ED - Ventriculite associada à encefalite disseminada. Grupo I (inoculado com VEV). 


\section{Reação de astrócitos - astrogliose}

Dois dias após a inoculação do vírus foram observados astrócitos com marcação positiva para a GFAP. As células apresentavam morfologia ativada, caracterizada principalmente por um núcleo grande e claro, cromatina em grumos, localizada na periferia da membrana nuclear, e nucléolo(s) grandes(s). O citoplasma mostrou-se evidente e os prolongamentos espessos, intensamente corados em marrom. Células com esta morfologia foram observadas no bulbo olfatório, principalmente nas regiões da glia limitante externa e nas camadas de células glomerulares e mitrais.

Outras áreas intensamente positivas para a GFAP foram o hipocampo, corpo caloso e cerebelo.Entretanto, seis dias após a inoculação do VEV, verificamos, nos camundongos sacrificados com sintomas neurológicos, uma redução na intensidade da reação revelada pelo DAB em algumas destas áreas, as quais apresentavam correspondência com áreas necrose do tecido nervoso.

\section{Distribuição do antígeno viral}

$\mathrm{O}$ anticorpo utilizado para detectar os antígenos virais mostrou boa especificidade na detecção dos antígenos em neurônios (Figura 2A). Dois dias após a inoculação, o vírus foi localizado apenas no bulbo olfatório. Todos os animais apresentaram marcação positiva nesta região, porém observamos variação de intensidade da marcação e na distribuição do antígeno viral neste ponto de sacrifício.

Nos dias quatro e seis após a inoculação, houve disseminação do antígeno e detecção do mesmo em áreas como o epêndima periventricular (Figura 2 B), hipocampo (Figura $2 \mathrm{C}$ ), corpo caloso, tálamo, hipotálamo, núcleos do mesencéfalo e núcleos do tronco cerebral. A detecção em áreas como o cerebelo (Figura 2D) e córtex cerebral foram menos freqüientes. A Figura 1A representa a frequiência de detecção da imunorreatividade ao antígeno viral em áreas encefálicas.

As áreas nas quais os neurônios apresentaram imunorreatividade ao anticorpo anti-VEV revelaram boa correspondência com aquelas que mostravam alterações degenerativas, quando observadas na hematoxilina e eosina. Em áreas com processo inflamatório intenso e necrose do tecido, a marcação para os antígenos do VEV apresentava-se com aspecto granular ou difuso.
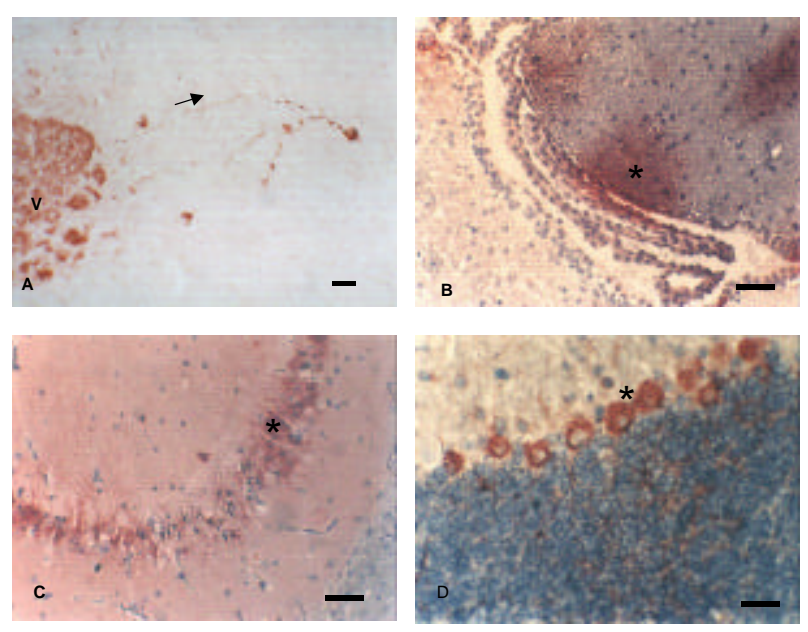

Figura 2 - A - Escificidade da reação de imunoistoquímica para a detecção do antígeno viral. Observar o trajeto de migração do virus (seta) a partir do ventrículo do bulbo olfatório (VBO) em direção ao corpo neuronal (AEC sem contracoloração. Barra $=30 \mu \mathrm{m}$. Detecção do antígeno viral B - no epêndima e região periventricular (*), C - em neurônios hipocampais (*) e D - em células de Purkinje (*). Em B, C e D. Barra $=25 \mu \mathrm{m}$. O método utilizado foi o da avidina-biotina-peroxidade, revelado com eticarbazol e contracorado com hematoxilina de Mayer (Grupo I Inoculado com $\mathrm{VEV}, 6^{\circ}$ dia p.i).

\section{Discussão}

Este modelo estabelecido inicialmente por Cox e Olintsky (1933), Sabin e Olintsky (1937a, 1937b; 1938a,1938b) teve alguns aspectos de sua patogenia em roedores caracterizados em trabalhos como os de Bruno-Lobo et al. (1968); Miyoshi Harter e Hsu .(1971) e alguns mais recentes como os de Huneycutt et al. (1993, 1994), Barna, Komatsu e Reiss (1996) e Christian et al. (1996), Cornish et al. (2001) e Van Den Pol et al. (2002). Para este trabalho, utilizamos camundongos C57B16 que, segundo Christian et al. (1996), apresentam resposta imune Th1, comparável à observada em camundongos Balb-c por Huneycutt et al. (1993 e 1994). 
Os sintomas clínicos da infecção pelo VEV, observados nos camundongos a partir do quarto dia após a inoculação, foram semelhantes aos descritos por Weiland et al. (1992) para o vírus da raiva. Christian et al. (1996) relatam o aparecimento de sintomas (redução de atividade e pêlos arrepiados) logo no primeiro dia após a inoculação intranasal do VEV, e a paralisia dos membros posteriores foi observada em alguns animais em torno do sexto dia. Por outro lado, Van Den Pol et al. (2002), que utilizaram um vírus recombinante da estomatite, não observaram sintomas evidentes. É provável que a diferença em relação aos sintomas e mortalidade dos camundongos neste e em outros experimentos sejam decorrentes de variação na idade dos animais, da dose do inóculo e/ou ainda de características inerentes ao sorotipo Indiana 2 utilizado. Além disso, nesse trabalho, o vírus da estomatite vesicular foi adaptado em camundongos através de passagem intracerebral enquanto que nos trabalhos realizados por outros pesquisadores o vírus utilizado para a inoculação dos animais foi mantido e propagado em cultura de células.

As principais alterações morfológicas observadas no encéfalo dos animais estão relacionadas na Figura 1 e foram similares às descritas anteriormente na literatura por Miyoshi, Harter e Hsu (1971) e Huneycutt et al. (1993), mas diferem em alguns aspectos das observadas por Van Den Pol et al. (2002) que relatam disseminação do processo inflamatório em apenas um camundongo do grupo estudado 8 dias pi. Dois dias após a inoculação do vírus, as lesões foram discretas e localizadas no bulbo olfatório, no qual também localizamos antígenos do vírus da estomatite. Após o quarto dia, observamos que a disseminação do vírus para outras regiões foi acompanhada do agravamento do processo inflamatório com evolução para meningite e ventriculite, o que resultou no aparecimento de paralisia grave em cerca de $50 \%$ dos camundongos. Embora os sintomas sejam semelhantes aos observados em casos de raiva, as alterações morfológicas resultantes da infecção pelo VEV são diferentes. Na encefalite induzida pelo VEV não são observadas inclusões e o infiltrado inflamatório é composto por polimorfonucleres neutrófilos, além de linfócitos e plasmócitos característicos das infecções virais. Também se observaram áreas de necrose, principalmente no bulbo olfatório, e ventriculite em alguns animais.

O VEV invade o SNC através do nervo olfatório, atinge o líquido cefalorraquidiano e posteriormente as células ependimárias (PLAKHOV et al., 1995). Também ocorre disseminação através do transporte neuronal retrógado e possivelmente anterógrado resultando em infecção aguda do SNC (FORGUER et al.,1991; PLAKHOV et al., 1995; VAN DEN POL et al. 2002).

Conforme sugerido por Komatsu, Barna e Reiss (1997), a variação de intensidade da marcação e da distribuição do antígeno viral no bulbo olfatório no início da infecção sugere maior ou menor eficiência da imunidade inata do hospedeiro, por meio da produção de óxido nítrico induzida pela IL-12. Pode também estar relacionada à infecção de diferentes populações neuronais que utilizam diferentes neurotransmissores (SHEPHERD \& GREER, 1990).

Quanto à localização do antígeno viral, a migração do vírus para regiões periventriculares em direção a regiões caudais do encéfalo foi bastante semelhante à observada por Huneycutt et al. (1994). Entretanto, também foram observados encéfalos com marcação positiva para os antígenos virais em neurônios corticais e cerebelares. Esta distribuição do VEV foi descrita em camundongos imunossuprimidos (HUNEYCUTT et al, 1993). É provável que esta distribuição dos antígenos esteja relacionada à utilização de sorotipos diferentes ou que a passagem intracerebral realizada para produção do inóculo tenha aumentado a virulência da amostra.

No presente trabalho detectaram-se células inflamatórias compondo o infiltrado meníngeo e em áreas de necrose do tecido nervoso. Existem evidências de que as células $T$ podem ser não apenas mediadoras da imunidade protetora, mas também 
indutoras de lesão imunopatológica (WELSH et al., 1997).

Sabe-se que a eliminação de vírus do SNC por meio de mecanismos mediados por células pode contribuir para o agravamento da doença (SEDGWICK , DÖRRIES, 1991). A participação da resposta celular no modelo que utiliza o VEV foi previamente estudada por Huneycutt et al. (1993), que observaram que a recuperação dos animais era dependente de células $\mathrm{T}$ imunocompetentes e sugeriram que os danos teciduais observados na infecção pelo VEV seriam decorrentes da multiplicação viral nas células neuronais, mas não descartaram a participação de resposta imune inespecífica do hospedeiro. Recentemente, comprovouse que o vírus da estomatite é capaz de induzir morte por apoptose em neurônios “in vitro", independente da sua multiplicação dentro das células (GADALETA,VACOTTO, COULOMBIE, 2002). Mesmo assim, não se pode ignorar que a produção local de citocinas pró-inflamatórias, derivados do ácido aracdônico, radicais livres e quimiocinas podem contribuir para o agravamento da lesão (TOULMOND; PARNET; LINTHORST, 1996; CAMPBELL, 1998; GHIRNIKAR, LEE; ENG, 1994). Além disto, a produção de citocinas tambémé realizada pela microglia, astrócitos, neurônios, células perivasculares e endoteliais (TOULMOND; PARNET; LINTHORST, 1996; CAMPBELL, 1998; GHIRNIKAR, LEE; ENG, 1994).

A observação de astrócitos GFAP positivos no bulbo olfatório dois dias após a inoculação confirmaram as observações de Bi et al. (1995), que descreveram resposta rápida à infecção pelo VEV, tanto de astrócitos como da microglia. Durante a infecção viral, geralmente são observados astrócitos reativos onde ocorreu lesão tecidual e a sua aparência é muito semelhante à observada após isquemia e edema crônico, por exemplo (ESIRI , KENNEDY, 1997). O envolvimento dos astrócitos nas encefalites virais tem sido objeto alguns estudos (ITOYAMA et al., 1991; RINAMAN et al., 1993; VANDEVELDE et al., 1983; ALESSI, 1991, MACHADO et al. (1993); MACHADO (1994).
Segundo alguns autores, a hipertrofia e a hiperplasia de células da glia também refletem o aumento de sua capacidade funcional (Norton et al., 1992; Summers et al., 1995). As funções destes fatores derivados da glia ainda não são bem compreendidas, mas eles podem contribuir potencialmente para o desenvolvimento das alterações patológicas observadas e, alternativamente, podem ser importantes para a recuperação do tecido lesado (RIDET et al., 1997).

Foi verificado que, devido à facilidade de manipulação do vírus, este modelo experimental tem sido utilizado em inúmeros trabalhos de pesquisa em diversas áreas. Uma vez que o vírus da estomatite vesicular apresenta alta taxa de mutação, os trabalhos realizados em diferentes laboratórios mostram algumas diferenças no que diz respeito à distribuição do antígeno e nas alterações morfológicas observadas. Se, por um lado, os relatos sobre a patogenia da infecção são numerosos, ainda existem muitas lacunas que envolvem, por exemplo, aspectos sobre a transmissão do vírus, a recuperação dos animais infectados e a participação de células gliais durante a fase aguda e a fase de recuperação dos animais.

\section{Agradecimentos}

A Dra. Magali D’Angelo do Laboratório de Cultivo Celular do Instituto Biológico de São Paulo pela titulação do vírus em microplacas e a Márcio Botelho de Castro pelo auxílio com as figuras.

\section{Referëncias}

ALESSI, A.C. Estudo experimental sobre a patogenia da encefalomielite murina de Theiler. 1991 Tese (Livredocência).- Faculdade de Ciências Agrárias e Veterinárias, Universidade Estadual Paulista, Jaboticabal.

BARNA, M.; KOMATSU, T.; REISS, C.S. Activation of type III nitric oxide synthase following a neurotropic viral infection. Virology, New York, v.223, n.2 p.331-343, Sep., 1996. 
BARRERA, J.C.; LETCHWORTH, G.H. Persistence of vesicular stomatitis virus New Jersey RNA in convalescent hamsters. Virology, New York, v.219, n.2, p.453-464, Sep.,1996.

BI, Z. et al. Vesicular stomatitis virus infection of the central nervous system activates both innate and acquired immunity. Journal of Virology, Washington, v.69,n.10, p.6466-6472, Oct., 1995.

BRUNO-LOBO, M. et al. Pathogenesis of vesicular stomatitis virus New Jersey infection in the adult hamster and mouse. Anais de Microbiologia (Rio), v.15, p.69-79, 1968.

CAMARGO, N.F. et al. A complement fixation technique for foot and mouth disease and vesicular stomatitis. Journal of The American Veterinary Medical Association, Schaumburg, v.117, n881, p.107-108, 1950.

CAMPBELL, I.L. Structural and functional impact of the transgenic expression of cytokines in the CNS. Annals of the New York Academic Science., New York, v.840, p.8383, May, 1998.

CHRISTIAN, A. Yet al. Host immune response to vesicular stomatitis virus infection of the central nervous system in C57B16 mice. Viral Immunology, Larchmont, v.9, n.3, p.195205, 1996.

CORNISH, T.E. et al. Pathogenesis of experimental vesicular stomatitis virus (New Jersey serotype) infection in the Deer Mouse (Peromyscus maniculatus). Vet. Pathol , Lawrence,. v.38, n.4, p.396-406, Jul., 2001.

ESIRI, M.M.; KENNEDY, P.G.E. Viral disease In: GRAHAM, D.I.; LANTOS, P.L. (Eds.). Greenfield's Neuropathology. London : Arnold,1997. p.3-63.

FORGER, J.M. et al. Murine infection by vesicular stomatitis virus: Initial characterization of the $\mathrm{H}-2^{\mathrm{d}}$ System. Journal of Virology, Washington, v.65, n.9, p.4950-4958, Sep., 1991.

GADALETA, P.; VACOTTO M.; COULOMBIE, F. Vesicular stomatitis virus induces apoptosis at early stages in the viral cycle and does not depend on virus replication. Virus Research., Shannon, v.86, n.1-2, p.87-92, Jun., 2002.

GHIRNIKAR, R.S.; LEE, Y.L.; ENG, L.F. Inflammation in traumatic brain injury: role of cytokines and chemokines. Neurochemical Research, New York, v.23, n.3, p.329-340, 1994.

GOBET, R. et al. The role of antibodies in natural and acquired resistance of mice to vesicular stomatitis virus. Experimental Cell Biology, Basel, v.56, p.175-180, 1988.

HOPKINS, S.J.; ROTHWELL, N.J. Cytokines and the nervous system I: Expression and recognition. Trends Neuroscience, Kidlington, v.18, n.2, p.83-88, Feb.,1995.
HUNEYCUTT, B.S. et al. Central neuropathogenesis of vesicular stomatitis virus infection of immunodeficient mice. Journal of Virology, Washington, v.67, n.11, p.66986706, Nov., 1993.

HUNEYCUTT, B.S. et al. Distribution of vesicular stomatitis virus proteins in the brains of $\mathrm{BALB} / \mathrm{c}$ mice following intranasal inoculation: an immunohistochemical analysis. Brain Research, Amsterdan, v.635, n.1-2, p.8195, Jan., 1994.

ITOYAMA, Y.et al. Early loss of astrocytes in herpes simplex virus-induced central nervous system demielination. Annals of the Neurology, Hangersstown, v.29,n.3, p.285-292, Mar.,1991.

KELLEY, J.M.; EMERSON, S.U.; WAGNER, R.R. The glycoprotein of vesicular stomatitis virus is the antigen that gives rise to and reacts with neutralizing antibodies. Journal of Virology, Washington, v.10, p.1231-1235, 1972.

KOMATSU, T.; BARNA, M.; REISS, C.S. Interleukin-12 promotes recovery from viral encephalitis. Viral Immunology, Larchmont., v.10, n.1, p.35-47, 1997.

LEIST, T.P. et al., M. Functional analisys of T lymphocyte subsets in viral host defense. Journal of Immunology, Bethesda, v.138, p.2278-2311, 1987.

LETCHWORTH, G.J.; RODRIGUEZ, L.L.; DEL EBARRERA. Vesicular Stomatitis. Veterinary Journal, London, v.157, p.239-260, 1999.

MACHADO, G.F. Mapeamento de astrócitos imunorreativos à proteína glial fibrilar ácida (GFAP) em SNC de bovinos normais ou naturalmente infectados pelo vírus da raiva. 1994, Dissertação (Mestrado) Faculdade de Ciências Agrárias e Veterinárias, Universidade Estadual Paulista, Jaboticabal.

MACHADO, G.F; LEMOS, K.R.; ALESSI, A.C. Aspectos sobre a distribuição de astrócitos e reação astrocítica em algumas afecções neurológicas dos animais domésticos.In: ENCONTRO NACIONAL DE PATOLOGIA VETERINARIA, 6., 1993, Santa Maria. Anais... Santa Maria, 1993. p.8.

MIYOSHI, K.; HARTER, D.H.; HSU, K.C. Neuropathological and Immunofluorescence studies of experimental vesicular stomatitis virus encephalitis in mice. Journal of Neuropathology and Experimental Neurology, Lawrence, v.30, p.266-277, 1971.

MOHAMED, A.K.H et al. Persistent changes in behavior and brain serotonin during aging in rats subjected to infant virus infection. Neurobiology Aging, New York, v.13, p.83$87,1991$.

NORTON, W.T. et al. Quantitative aspects of reactive gliosis: A review. Neurochemical Research, New York, v.17, p.877-885, 1992. 
OWENS, T. et al. Inflammatory cytokines in the brain: does the CNS shape immune responses? Immunology Today, Limerick, v.15, n.12, p.566-571, 1994.

PLAKHOV, I.V. et al. The earliest events in vesicular stomatitis virus infection of the murine olfactory neuroepithelium and entry of the central nervous system. Virology, New York, v.209, n.1, p.257-262, 1995.

REED, L.J.; MUENCH, H. A simple method of estimating fifty percent end points. American Journal of Hygiene, Baltimore, v.27, p.493-497, 1938.

RIDET, J.L. et al. Reactive astrocytes: Cellular and mollecular clues to biological function. Trends Neuroscience, Kindington, v.20, p.570-577, 1997.

RINAMAN, J.; CARD, J.P.; ENQUIST, L.W. Spatiotemporal responses of astrocytes, ramified microglia and brain macrophages to central neuronal infection with pseudorabies virus. Journal of Neuroscience, Washington, v.13, p.685-702, 1993.

ROSENTHAL, K.L.; ZINKERNAGEL, R.M. Cross-reactive cytotoxic $\mathrm{T}$ cells to serologically distinct vesicular stomatitis viruses. Journal of Immunology, Bethesda v.124, p.2301-2308, 1980.

SABIN, A.B.; OLINTSKY, P.K. Influence of host factors on neuroinvasiveness of vesicular stomatitis virus. I. Effect of age on the invasion of the brain by virus instilled in the nose. Journal Experimental of Medicine, New York, v.66, p.15-33, 1937a.

Influence of host factors on neuroinvasiveness of vesicular stomatitis virus. II. Effect of age on the invasion of peripheral and central nervous system by virus injected into the leg muscles or the eye. Journal Experimental of Medicine, New York, v.66, p.35-57, 1937b.

Influence of host factors on neuroinvasiveness of vesicular stomatitis virus. III. Effect of age and pathway of inflection on the character and localization of lesions in the central nervous system. Journal Experimental of Medicine, New York, v.67, p.201-227, 1938a.
Influence of host factors on neuroinvasiveness of vesicular stomatitis virus. IV. Variation in neuroinvasiveness in different species. Journal Experimental of Medicine, New York, v.67, p.229-249, 1938 b.

SEDGWICK, J.; DÖRRIES, R. The immune system response to viral infection of the CNS, Neuroscience, Kidlingtonn, v.3, p.93-100, 1991.

SHEPHERD, G.; GREER, C.A. Olfactory bulb, In: SHEPARD, G.M. (Ed.). Synaptic organization of the brain. Oxford : Oxford University, 1990.

SUMMERS, B.A.; CUMMINGS, J.F.; LAHUNTA, A. de (Eds.). Veterinary Neuropathology. St. Louis : MosbyTime Life, 1995.

SY, M. S. et al. Effect of vesicular stomatitis virus (VSV) infection on the development and regulation of $\mathrm{T}$ cellmediated immune response. Journal of. Immunology, Bethesda, v.131, n.1, p.30-36, 1983.

TOULMOND, S.; PARNET, P.; LINTHORST, A.C.E. When cytokines get on your nerves: Cytokine networks and CNS pathologies. Trends Neuroscience, Kindlington, v.19, n.10, p.409-410, 1996.

VAN DEN POL, A.N.; DALTON, K.P.; ROSE, J.K. Relative neurotropism of a recombinant rhabdovirus expressing a green fluorescent envelope glycoprotein. Journal of Virology, Washington, v.76, p.1309-1327, 2002.

VANDEVELDE, M. et al. Glial proteins in canine distemper virus-induced demielination. Acta of Neuropathology, Berlin, v.59, p.269-276, 1983.

WEILAND, F. et al. Rabies virus neuritic paralysis: immunopathogenesis of nonfatal paralytic rabies. Journal of Virology, Washington, v.66, n.8, p.5096-5099, Aug, 1992.

WELSH, R.M. ab and gd T-cell networks and their roles in natural resistance to viral infections. Immunology Review, Copenhagen, v.159, p.79-93, Out, 1997. 